\title{
"We're not just sat at home in our pyjamas!": a thematic analysis of the social lives of home educated adolescents in the UK
}

\author{
Eloise de Carvalho $^{1}$ (D) Yvonne Skipper $^{1}$ (D)
}

Received: 31 May 2017 /Revised: 30 May 2018 / Accepted: 3 July 2018 /

Published online: 21 July 2018

(C) The Author(s) 2018

\begin{abstract}
A common perception of home education is that despite potential beneficial educational outcomes, children who are home educated lack social experiences and therefore show poor social development. However, previous research in this area suggests that home educated children demonstrate a range of age-appropriate social skills. This research has mainly focused on children younger than 12; thus, we have much less of an understanding of the social impacts of home education on adolescents. Furthermore, previous research has often used social skills questionnaires and has not explored the experiences of home educating families from their own perspectives. The current study addresses these gaps in the literature by interviewing three home educated adolescents and their mothers about their social experiences and development with the research question of 'how do home educated adolescents and their parents experience and understand socialisation?'. In one-to-one interviews, young people (aged 11-14) were asked about their experiences and perceptions of their social lives. In a separate interview, mothers were asked about how they facilitated these social experiences and their perceptions of the impact this had on their child's development. Data from the interviews was thematically analysed. Results suggested that adolescents participated in a range of social experiences that promoted their social skills, happiness and confidence. Participants felt that this created a positive social environment and sense of community, and encouraged the adolescents to interact with a diverse range of people. However, further research is needed to explore whether this finding is generalisable to the broader community of home educated adolescents.
\end{abstract}

Keywords Home education · Socialisation · Homeschooling · Social experiences

Eloise de Carvalho w0u78@students.keele.ac.uk

Yvonne Skipper y.skipper@keele.ac.uk

1 Department of Psychology, Keele University, Staffordshire ST5 5BG, UK 
Elective home education is described as "parents' decisions to provide education for their children at home instead of sending them to school" (Department for Education 2013, p. 3). In the UK, home education is on the rise: the number of children recorded by local authorities as 'home educated' has doubled in the last 6 years (Staufenberg 2017). However, it is difficult to accurately estimate the number of children who are being home educated in the UK because parents are under no obligation to register their intent with the local education authority. A freedom of information request to local authorities indicated that 29,805 children are currently home educated (Staufenberg 2017). Nevertheless, because this figure only relates to 86 out of 152 councils, the actual number is likely to be much larger. This demonstrates the importance of better understanding experiences of home education.

In the USA, Ray's (2013) systematic review found that perceptions of home education amongst educators were predominantly negative. This negativity included concerns regarding a lack of sense of community and prevention of social interaction. According to Romanowski's (2006) review, the most common concern about home education is that it produces social misfits. It is often believed that home educated children are isolated from the outside world and thus lack the social skills necessary to function in society. Therefore, the primary concern surrounding home education appears to be centred not on education but socialisation.

Romanowski (2006) observed that many people assume that conventional schooling offers socialising experiences that home education cannot, such as team sports. Yet, many home educated children take part in numerous activities to aid social development, such as dance classes, the Scouts, and volunteer work (Romanowski 2006). While these experiences are also available to conventionally schooled children, the greater flexibility of home education may allow young people to spend more time in these activities and allow them to participate in a wider range of opportunities. Furthermore, perhaps some of the social interactions experienced in schools are not the kind that parents want their children to be involved in; bullying is prevalent in many schools, with The Annual Bullying Survey (Ditch the Label 2015) reporting $43 \%$ of young people as having been victims. Lebeda (2007, p. 99) states, "Go to your local middle school, junior high, or high school, walk down the hallways, and tell me which behaviour you see that you think our son should emulate". Thus, while schools offer many opportunities to develop social skills, these interactions may not always be positive.

\section{Socialisation for home educated children}

Socialisation can be defined as the continuing process of modifying behaviour to conform to the demands of social life (Socialisation 2012). It is comprised of many aspects including social activity, social influence and social exposure (Medlin 2000). Discussion of 'socialisation' in relation to home education typically refers to the social experiences of the child (created by social activity, influence and exposure) and their effects on social development.

Because home education is often considered 'alternative' by society (e.g. Kraftl 2013), families may choose to socialise together to connect with others who have made similar choices about education. This interaction may mean they are less likely to feel marginalised by their choice and can find validation as well as a sense of community. Within this sphere, families can construct what education and socialisation means for them in their community. Social representations are the collective values, ideas and practices that facilitate orientation in the social world and enable communication between members of the sphere (Obradovic and 
Howarth 2017). The current research is therefore interested in the social representation of socialisation in home education.

Research suggests that the negativity and concerns around socialisation of home educated children are for the most part unfounded. In two recent reviews, Kunzman and Gaither (2013) and Medlin (2013) concluded that home educated children performed comparably to their conventionally schooled counterparts across a range of skills important for social interaction, including co-operation, empathy, assertion and self-control. Furthermore, they engaged in a wide variety of experiences, including home education networks that provided opportunities for social interaction. Although the format of home education networks varies, they typically involve parents organising (often regular) activities and events for their children and other local home educating families. These may include trips to museums or simply meetings in shared spaces. These networks are popular in the UK (Fortune-Wood 2006).

Additionally, Medlin (2007) compared social skills scores of home educated children with standardised scores and found that social skills scores for some age groups were significantly higher than the norms, and no age group within the home educated sample scored significantly lower than the norms. However, Valdez (2005) surveyed home educated and conventionally schooled children and their parents and concluded that although there was no significant difference in social skills scores between the two groups, home educating parents rated their children's scores as significantly higher than did the other parents. This suggests that caution should be exercised when interpreting parents' reports of their children's skills, perhaps because home educating parents may see themselves as the primary socialising agents of their children and therefore may give an inflated positive report of their children's skills.

Nevertheless, the literature appears to demonstrate that the social skills of home educated children are at least equal to those of conventionally schooled children. Yet, while the majority of research has focused on the demonstration of social skills, it is important to consider other factors that contribute to social development, such as experiencing a sense of community and belonging to diverse social networks (Parke and Clarke-Stewart 2011).

\section{Sense of community}

At school, a sense of community is developed when children and staff share goals and values, support each other and believe that everyone contributes to school life (Osterman 2000). Osterman (2000) found that a strong sense of community at school promoted more prosocial behaviour, less disruptive behaviour and less emotional distress for pupils. A strong sense of community also supports a child's developing social identity by encouraging ingroup favouritism, which increases self-esteem (Hogg and Abrams 1990). Home educated children lack this formal school setting but may have the opportunity to develop a sense of community and social identity within other social groups, such as home education networks or clubs.

\section{Diversity}

It has also been argued that schools give children the opportunity to interact with others from diverse backgrounds, e.g. different ethnicities and academic abilities, which encourages acceptance of diversity (Parke and Clarke-Stewart 2011; Renninger 1998). Granovetter (1973) highlighted that a varied social network is vital for encouraging children to seek new information and opinions. However, Nelsen (1998) suggested that the mixing of diverse children does not truly occur in school as children are placed in classes with the same small 
group of children of the same age. In addition, schools do not often have high levels of ethnic and socioeconomic diversity due to drawing pupils from a small geographical area. Even when there is high diversity, there are low proportions of friendships across cultural boundaries (Vervoort et al. 2011). Romanowski (2006) suggested that because home educated children are not grouped as in school they have greater opportunity to mix with a more diverse group of individuals. For example, home education networks often include children from a variety of ages and backgrounds socialising and learning together. Additionally, children may be involved in a number of different networks, comprised of different individuals. This is thought to lead home educated children to be socially mature and able to adjust to new situations (Medlin 2013). However, it is not clear how home educating families view these communities and the impact they have on socialisation.

\section{The changing roles of the parent and the child}

Parents play important roles in the socialisation of their child by creating social experiences, for example by organising opportunities to have other children visit or by teaching their child to take turns and share. Parents also mediate the effect of other social influences, such as peers, e.g. by encouraging children to develop some friendships over others (Collins et al. 2000). It has been argued that parents are their child's main 'agent of socialisation' (Berns 2012). All parents are involved in socialising their children, but for home educating parents, the necessity of creating social experiences for their children is perhaps even more important than for a parent of a conventionally schooled child who might be offered other opportunities during the school day.

However, as children age, the socialising role of the parent changes. For example, joint decision-making increases during adolescence when young people begin to have more input in choosing their own social experiences (Wray-Lake et al. 2010). As much of the home education research, including an extensive study by Rothermel (2002), focuses on primary school-aged children (11 and under), very little is known about how social processes, such as joint decision-making, develop in home educated adolescents.

Fortune-Wood (2005) highlighted that significantly fewer adolescents participate in home education network meetups than primary-aged children. This is perhaps surprising considering that, when expressed as a percentage of all children their age, three times as many children are known to be home educated at the ages of 15-16 than at ages 5-11 (Fortune-Wood 2006). This suggests that home educated adolescents and their families rely less on home education networks than younger children and may find socialising opportunities elsewhere (FortuneWood 2006). This may be because young people have started to develop their own friendships and are choosing different socialising opportunities. However, it is not well understood where adolescents in the UK find socialisation opportunities and how this impacts on their social development. Thus, the current study aims to explore how home educated adolescents socialise and their perceptions of the impact this has on their social development.

\section{The current study}

There are a number of issues with current research on home education, which this study aims to address. Firstly, much of the research concerning home education is conducted in the USA. Eddis (2015) highlighted that the UK is at an earlier stage in its development of home education with a smaller population and less visible support groups and networking opportunities. As such, research from the USA is not always applicable to the home educating population of the UK. 
Additionally, development of social skills in home education is generally measured using social skills questionnaires. However, these do not consider the processes of how and/or where the child acquires these social skills or the child's own views of their social experiences. Greig et al. (2012) highlighted the significance of the voice of the child as an expert on their own experiences and how this is often overlooked and dismissed as insufficient. Qualitative methods, such as interviews, employ an explorative aspect by allowing participants to expand on their answers to questions and introduce new ideas for the interviewer to explore (Brinkmann 2014). Medlin (2013) identified that researchers could learn more from shifting their focus from the outcomes of socialisation to the process and how parents facilitate it. Reflection on development of social skills instead of skill level can also encourage honesty and accuracy in participants' responses. Thus, in this study, adolescents were interviewed to allow exploration of their views on their socialisation.

As it is ultimately the parents' decision to home educate, it is likely that they will have strong opinions regarding the socialisation of their children. Thus, it would be valuable to also explore the roles and views of home educating parents, such as reasons for home education and how they support their child in providing socialisation opportunities. Literature (e.g. Medlin 2000) has previously identified this for younger children, but does not consider what happens as children mature and become more independent and how the dynamic of the relationship might change (e.g. Wray-Lake et al. 2010).

Thus, this study explores the social lives of UK home educated adolescents; in particular, the experiences of the child and the role of the parent in socialising. The study used one-to-one semi-structured interviews to gain insight into the views and experiences of the home educated adolescents and their mothers. Prompts, in the form of social interaction diaries for the adolescents and reflection sheets for the parents, were distributed prior to the interviews to encourage participants to reflect upon their social lives so that they could answer questions in as much detail as possible. We aimed to address the question: 'How do home educated adolescents and their parents experience and understand socialisation?'

\section{Method}

\section{Participants}

Three White British home educated girls aged between 11 and 14 and their mothers were recruited as an opportunity sample via online recruitment methods. Alice is 11 years old and lives in the Midlands; she has autism spectrum disorder (ASD). Her mother Maria has been home educating her for the past 12 months after feeling that the school were not meeting Alice's needs. Sophie is 13 years old and lives in Northern England. Her mother Gina has been home educating Sophie since she was old enough for compulsory education. Beth is 14 years old and lives in Northern England. Her mother Lucy has been home educating her for the past 15 months after removing Beth from school because of poor social experiences.

\section{Materials}

Two-week social interaction diaries were completed by the adolescents prior to interview to act as a prompt. For every interaction lasting longer than $10 \mathrm{~min}$, adolescents were asked to complete a short, structured diary entry, which included sections on details of the interaction, 
who was involved and emotions experienced. This was based on the Rochester Interaction Record (Reis and Wheeler 1991), which assesses objective and subjective aspects of social interaction to aid detailed and accurate recall. However, these were only used by the participants as a recall aid and were not examined by the researchers. This allowed participants to be honest in recording their interactions without having to reveal anything they did not wish to the researchers.

To prepare parents for their interview, a structured reflection sheet asked them to reflect on their role as a home educating parent and their influence on their child's social life. It included prompts, such as 'how do you think home education affects your child's socialising opportunities?' and 'what social educational experiences does your child take part in (if any)?'.

Two interview schedules, one for adolescents and one for parents, were used to guide the interviews. The questions were based on various aspects of social experiences within home education, including the practice itself, the adolescents' social networks and the effect that home education had on adolescents' social development. For example, adolescents were asked 'how often do you meet with other home educated children?' and parents were asked 'where do you find opportunities for your daughter to socialise?'

\section{Procedure}

Emails with information about the study were sent to home education network mailing lists and placed on home education social media spaces. Parents were asked to contact the researcher to indicate their interest in participating in the research. To reduce pressure of participation, separate consent sheets were sent via email to parents and adolescents, informing them about the study, including confidentiality and their right to withdraw. Participants were told that they might be contacted if both consent emails were returned, which allowed us to gain consent from both parties without either feeling pressure to participate. Once consent was received, the date and location were arranged for interviews. Adolescents were then sent social interaction diaries, which they were asked to complete every day for 2 weeks. On the day of the interview, the child was interviewed first, while the parent completed the reflection sheet; the parent was then interviewed.

The semi-structured interviews lasted approximately $40 \mathrm{~min}$. Participants were encouraged to be honest in their responses and were reminded of confidentiality. During the interview, the social interaction diaries and parent reflection sheets acted as prompts for participants to help them describe their social experiences. Audio recordings of the interviews were taken and transcribed verbatim in a 'play script' format. Any identifying personal information was removed from the transcripts and participants were given pseudonyms. The social interaction diaries and parent reflection sheets were not retained by the researchers. After the interviews, participants were sent debrief emails that fully explained the study.

\section{Analytic method}

Thematic analysis was conducted on the data from the interviews to identify and organise themes, guided by the steps outlined by Braun and Clarke (2006). First, transcripts were read thoroughly, with notes made in the margin every couple of sentences to generate initial codes, e.g. 'communication with different ages'. These initial codes were collated into summary tables for each participant, to determine their frequency. A mindmap was used to organise codes into meaningful groups, which became initial themes: "coherent and meaningful 
pattern[s] in the data" (Clarke and Braun 2013, p. 120), e.g. 'sense of community'. The predominant themes were those most prevalent in the interviews. Transcripts and themes were continually consulted to ensure that all themes were fully explored and representative of the data; supporting quotes were selected. Patterns and commonalities were established across transcripts and discussion between first and second authors assisted in refinement of themes.

\section{Analysis}

In the six interviews, three predominant themes prevailed: sense of community within home education networks, diversity of their social experiences and networks, and the importance of choice in socialising opportunities. These will be explored separately below using illustrative quotes from participants (pseudonyms in parentheses).

\section{Sense of community}

Home education networks were discussed by all participants as being beneficial and providing a medium for families from a variety of backgrounds to become a community. Parents and adolescents both expressed positive feelings towards being part of the networks and meeting with other home educating families. Parents reported using the network as a way of making friends with other families and as a means of support:

If it wasn't for those groups, she probably wouldn't see all the children that she does in the week, so I think it's fantastic. When I first took her out of school I had no idea that all that existed, it was just amazing, you know, and some of the groups that I'm on on Facebook when mums are putting on questions like, 'How do we do it? Blah blah blah', you know, it's just reassuring that there is no problem meeting people because there's just so many parents doing it and so many kids out there to hook up with... (Lucy, Beth's mother)

Lucy, and the other mothers, discussed the ease of creating socialising opportunities for families through online groups. Lucy also suggested that perhaps this online presence is not as visible to those outside of the home educating community. The mothers also actively participated in the networks by organising activities and groups that attracted other home educated children, which helped to expand the adolescents' social circles:

And we started, you know, we did these groups, the art group and the book group simply to get other people... you know, for her to socialise with other people. And that was the whole aim of them really, not academic-wise because academically I could teach her everything she needs to know perfectly well but that's not everything that is important..... (Maria, Alice's mother)

Maria highlighted socialising as the primary reason for setting up regular group meetings for her child and other home educated adolescents in their local area, above the academic benefits. This illustrates that she was considerate of social development as well as academic development. Additionally, Maria emphasised that while she could teach academic skills, interaction with peers was important to develop social skills. Within such groups, Gina 
reported that a shared interest in home education helped to create a strong social network for parents:

And I just like the home educating community, you know, you don't get people who haven't given a moment's thought to their kids' education. I mean nobody comes into it by accident.... There's not a single person who hasn't given a lot of thought to what's best for their child, and they're just lovely people to be around. People who actually really, really like and want to do the best for their kids. (Gina, Sophie's mother)

Gina emphasised that the common interest in their adolescents' education and socialisation created a positive environment when families met up, which reinforces the strong sense of community, and indicates a sense of shared identity between parents. The adolescents also experienced a similar sense of community within home education networks, predominantly through a sense of acceptance and understanding from other children:

Because I think most home educated kids have been bullied so they know how it feels, so they're not horrible. And they're so nice, and then like, at school, some kids are really horrible and it's just, I feel like home education kids are like... they've been through the same thing so they know how it feels so they're nice to people. So yeah, I just feel like, when I walk into places, like, everyone's got smiles on their faces, or even if like, I'm still a bit shy sometimes, but like when I go to groups like, people come up to me... (Beth, 14)

Beth suggested that sharing similar, sometimes negative, experiences at school made home educated adolescents more welcoming and highlighted the positive environments of the groups. This suggests that, for our participants, home education network meetings provided a space for young people to have positive interactions with others, which contrasted with previous school experiences for Beth and Alice. Overall, the mothers and adolescents experienced a strong, positive sense of community in their local home educating networks and found it easy to find and create socialising opportunities.

\section{Diversity in social experiences}

Both parents and adolescents expressed the opinion that socialising through home education could be better than the socialising typically experienced at school due to greater diversity. Diversity in socialising was predominantly discussed through the range of regular activities and different networks that the adolescents participated in, both within and outside of the home educating community:

Well like, I do my drama on a Saturday and then I do this drama, [theatre group], on a Monday, and then I go to one on a Friday, which is like home education, like it's from little kids to older kids, so yeah. And sometimes the parents organise activities so like, I went to Crown Court and we did like a play... We've done like, raft building... I've done pottery... What else have I done? There's so much I can't even remember! There's just like, different groups that come up and says, 'oh, well we're organising this that day' and things like that. (Beth, 14) 
Beth's quote demonstrates that she chose from a range of social opportunities offered by different branches of the local home education network, which are comprised of different circles within the community. Beth also highlighted that a key difference from the school environment was that learning with the home educating community was more social:

So like, I'd say [home education] it's more social than actual being in school because when you're in school you have to do lessons and you're not allowed... well you are allowed to talk... and then you only have fifteen minute breaks. But when you're home educated, it's learning but then like, when you're doing things, you're in groups and you're doing teamwork and you meet lots of new people... (Beth, 14)

Beth discussed an increased quality and positivity of socialisation during learning experiences; she reflected on a more collective nature of learning, e.g. group work, which implies the feeling of a shared endeavour, possibly contrasting with her social experiences at school. In terms of the diversity of the community, Gina also felt that due to the individual nature of home education (e.g. the number of ways to practise it and the range of reasons for participating in it), the home educating community was comprised of people from a variety of backgrounds:

You just tend to mix with people from a wider geographical area, a wider... social strata? ... And we've learnt so much about different people's religions and things that I think you just end up a bit more accommodating, because there's always somebody who can't or won't do something because of X, as opposed to, everybody has to do this. And the fact that you can opt out... 'Oh why isn't such-and-such-a-bod here?', 'Oh well, it's Ramadan'... There's no way I'd have a ton of Muslim friends I don't think because it's not a heavy Muslim area, so if my friends came from the school gate, you know, I wouldn't have that network at all. (Gina, Sophie's mother)

Gina highlighted the positive effects of learning and acceptance that a diverse community can encourage, and the diversity that she and her daughter experienced by socialising with families from different religions and socioeconomic groups. Participants also expressed the benefit of socialising with adults, particularly in a more egalitarian manner than a typical teacher-pupil relationship:

I don't think a lot of people realise, the sort of socialising we do, like we drop [Alice's] brother off at nursery ... the teachers will talk to her, ask her how she is and she plays with some of the little ones.... That kind of social interaction is so important. Other children in school do not get but she gets that... I think that kind of, you know, interacting with younger children, adults, and adults who treat you like you're important... (Maria, Alice's mother)

Maria suggested the importance of quality communication with different age groups. One of the reasons that Maria and Lucy decided to remove their children from school was poor social experiences, which negatively impacted on their wellbeing. Maria expressed how Alice has thrived since leaving the school environment and being able to mix with a more diverse range of people: 
[Alice] has learnt that she can communicate better with children who are different ages to her.... And I think she also realises that there are children who... do not have all the things that she likes about someone but she can still be friends with them.... And I think... with me there to help guide her, I think it's helped her to form relationships that she wouldn't otherwise have done.... (Maria, Alice's mother)

Parents being present during groups and activities was identified as being typical of social experiences in the home educating community, and Maria highlighted this as a way to support her daughter in developing social relationships. This is probably easier to do for parents who are home educating than for teachers in the playground who may have oversight of a large number of children and may not notice those who are struggling. For the adolescents, greater diversity was expressed through the individuality of home educated children and how this diversity created less pressure to conform than perhaps conventionally schooled children:

I'd say home education kids are a bit more... they're a bit more quirky.... They can be themselves, like, I found a lot when I was at school I couldn't be myself and my mum didn't like that, like, she wanted me to be myself. (Beth, 14)

Beth alluded to home education, with its community of varied personalities, as providing an environment to develop her individual identity. In summary, the adolescents and mothers felt that they socialised with a diverse group through home education networks, including different age groups, which they believed improved social skills and viewed as superior to the quality of social interaction experienced at school.

\section{Importance of choice in socialising}

Parents mainly held the authority with regard to making arrangements for their adolescent's socialising, but they shared the decision-making with them, i.e. what opportunities their adolescent took part in. The adolescents often proposed ideas; for example, Sophie illustrated the adult-organised but child-directed approaches to choosing structured activities to participate in:

Often, mum finds [socialising opportunities] and then says, 'Do you fancy that?'.... But often I get my own thought in it. ... Or say, like with the trampolining, I only took that up quite recently but it was only because I had Wednesday and Friday doing nothing. ... She said, 'Do you want to do anything?'. I said, 'Well I'd like to do trampolining but I know that's impossible', but then she found a group and I got to start it. (Sophie, 13)

This demonstrated that while her mother endeavoured to fill free days with social activities, Sophie was encouraged to choose the experiences that she participated in, and her mother even arranged an opportunity that her daughter did not think was feasible. Sophie reported the aspects of choice and freedom as being a highlight of home education in general:

You probably have a lot more freedom [in home education] I think, for me, freedom is a big thing as well. I think you should have a choice really, instead of having to be forced to go to school. (Sophie, 13) 
Sophie suggested that home education perhaps contrasts to the school environmentdespite never having been - in terms of the degree of freedom and choice that it offers. The associated freedom, choice and informality was reflected in the adolescents' social lives. Every child had individual socialising preferences: Alice, for example, sometimes found socialising hard and disliked big social groups, which may be a product of her ASD (though this was not mentioned by Alice nor her mother). Home education removed the pressure for Alice to interact with those her own age and gave her the freedom to socialise on her own terms:

I find it really hard socialising with my year group; I find it easier with older children and younger children. Because [brother], who's the youngest out of all of us, he's my most... I'm more close to him than any others... I just find that people my age are a bit more annoying and talkative than younger or older children. (Alice, 11)

This freedom of choice around socialising was seen as leading to more positive wellbeing and meant that Alice was able to socialise with young people of a range of ages. This may have increased the diversity of her social network. However, through the importance of choice, the mothers highlighted a limitation of socialising with the home education network: many of the available activities and groups were targeted at younger children:

I think older girls particularly find it hard to force friendships with other girls... And also teenage girls do not necessarily want to be forced to socialise with teenage boys... So, I think the activities that you do for teenagers have to be something less forced ... so that they can go and do their own thing and maybe come together if they want to, rather than a group where you're forcing them to work together and they might not want to. I think it's quite difficult to know how to do that. (Maria, Alice's mother)

Maria suggested that perhaps adolescents prefer a more informal kind of socialising, which is not currently as widely offered in their home educating networks. This is possibly because it is difficult to successfully set up such opportunities. However, Lucy reported that this was something she was exploring:

So recently, I've started communicating with someone that's local to us about trying to set up a group just for teens. Some of the things as well, you know, I don't mind myself trying to organise stuff. (Lucy, Beth's mother)

Attempting to fill this gap for teenage socialising opportunities by setting up new groups is another example of the parents' investment in promoting a fulfilling social life for their adolescents. On the whole, the adolescents felt that they experienced a high degree of choice in their social experiences in terms of the activities and their social contacts, and the mothers were eager to facilitate opportunities.

Overall, findings from the thematic analysis suggested broad agreement between the adolescents and their mothers about the benefits of home education on adolescents' social lives. This is interesting as the participants were different in terms of their experiences and reasons for home education. Perhaps, this similarity reflects a shared social representation of socialisation within the broad home educating community as being a strong and diverse community that encourages free choice in social opportunities. 


\section{Discussion}

\section{Summary}

Results suggest that our participants engaged in a variety of social experiences. Many of these were with their local home educating networks, which challenges Fortune-Wood's (2005, 2006) conclusions of low adolescent participation. Part of the reason for this discrepancy appears to be that the mothers in this study identified themselves as being highly involved in organising opportunities for their daughters and other home educating families. Parents and adolescents felt that the socialising experiences available to them were superior to the socialising experiences offered by school because of the range of activities they were able to regularly participate in with diverse groups of people and because of the element of choice in what they did.

For our sample, home educating networks were important for bringing families together and creating a sense of community. This community can then help them to develop social representations around home education in order to help them create a shared understanding of their practices and bring the community together. This may be particularly important for those engaged in 'alternative' lifestyles, where they may feel under pressure to justify their choices as they are non-normative. For home educators, the process of creating social representations may be that networks act as a sphere for the mothers and children to 'anchor' their shared ideas about socialising, e.g. the importance of diversity of social experiences. The mothers then 'objectify' this by creating such diverse social experiences for their children, e.g. trips to the court, which the adolescents positively engage in. Thus, these networks not only facilitate social interaction but through social representations help construct shared identities for parents and adolescents (e.g. Howarth 2002).

The repeated reference to the home educating community throughout the interviews ultimately highlights the provision available for those within this community. This perhaps suggests that Eddis' (2015) observation of a lack of visible support and opportunities for home educating parents and children is likely due to its marginalisation. For those in it, the home educating community, as perceived by these participants, is strong, diverse and thriving.

The network-organised groups were seen as diverse in terms of age, religion and geography. This supports Romanowski's (2006) conclusions that home educated adolescents often have a diverse social network. According to Granovetter (1973), the adolescents can use this network to gain new information and opinions. The adolescents particularly felt that the diversity in age groups was beneficial and very different to school. Intergenerational interaction and socialising within adult spheres can encourage the transmission of social norms (Costanzo and Hoy 2007), which could explain why many home educated children are noted as being mature. In fact, Smedley (1992) suggested that conventionally schooled children are socialised more horizontally to conform to their peers, while home educated children are socialised more vertically towards responsibility and adulthood. This may be beneficial, for example for younger children, however, during adolescence, horizontal socialising may become more important (e.g. Arnett 2000) as young people begin to develop a sense of identity independently of their parents.

The girls made emotional connections with the other young people in the networks who they felt were friendly and accepting. This high level of acceptance of individuality was suggested to be because many other home educated young people also had negative experiences of school. According to Osterman (2000), this acceptance is likely to aid the girls' 
prosocial behaviour and provide emotional support, which may help them develop and maintain their social identities and increase self-esteem (Hogg and Abrams 1990).

Parents viewed socialisation as an important part of their role in home education, and thus facilitated many socialising opportunities for their adolescents. Parents mainly held the authority with regard to making arrangements, but they also shared the decision-making with their adolescents who tended to propose ideas. This is consistent with Wray-Lake et al.'s (2010) conclusion that joint decision-making increases as the child reaches adolescence, which has been found to have positive impacts on development, including improved self-regulation and impulse control (Steinberg et al. 1991). As our sample were early in adolescence, this may be the precursor to more horizontal socialisation, which may become more salient with age. This was reflected in parents wanting to facilitate opportunities for teenagers to interact with less direction and input from parents.

Overall, adolescents enjoyed the majority of their social experiences because they were able to choose the opportunities they participated in. This reduced the pressure of forced socialising with others. Both Alice and Beth had been removed from school because of poor social experiences, which negatively affected their wellbeing. Since joining the home educating community, they had enjoyed the freedom to socialise as they chose, feeling happier and more confident. Such positive character outcomes echo Murphy's (2014) findings of home education resulting in increased positive self-concept and life satisfaction. Parents reinforced this dedication to promoting wellbeing by not encouraging their daughters to participate in opportunities that involved forced socialising, which they felt to be particularly essential as their daughters entered adolescence.

\section{Reflections}

This study provided an insight into the social lives of three UK home educated adolescents and the roles of their mothers. The interviews explored the adolescents' lived experiences and used records of their social interactions as prompts. The social interaction diaries were used to reduce the social desirability bias typically seen in questionnaire based studies, e.g. Valdez (2005), because they should act as a true record of the adolescents' social experiences. The study recognised the importance of the voice of the adolescents and their mothers to draw on their knowledge and experiences (Greig et al. 2012; Medlin 2013). It also highlighted the importance of conducting research with adolescents to recognise the significant role that they play in decision-making and determining their own social experiences.

However, the current study only explored views of mothers and their daughters. Rose and Rudolph (2006) noted gender differences in socialising, e.g. girls were more likely to participate in more social conversation and self-disclosure, and were more likely to seek support from friends in times of stress; they were also more likely to report experiencing emotional benefits of dyadic friendships, including feelings of security, affection and enhancement of worth. As well as this, the role of mothers is traditionally seen as bringing up the children and they tend to be more involved in their children's lives (Milkie et al. 2002). This could suggest that findings may have been quite different if the sample included males, both as children and as parents. Therefore, future research could explore a more diverse sample of young people and their parents.

A further limitation of this study is the use of opportunistic sampling, which was the most convenient sampling method but is likely to result in an unrepresentative sample - a common problem in home education research (Kunzman and Gaither 2013). It can be difficult to engage 
with potential research participants in the UK because families do not have to register themselves as 'home educating'. This could have resulted in self-selection bias in that dyads who replied to the recruitment email were already part of a home education network, and thus are more likely to have a strong interest in their child's socialisation and participate in many social experiences. Coupling the sampling bias with the small sample size, the findings from this study are not likely to be generalisable to other home educating families who are not involved in a network. Indeed, the positive experiences reported by participants may not be representative of other home educating families: Murphy (2014) recognised that much anecdotal evidence surrounding home education does not paint a rosy picture. Despite this, it is important to recognise that although the participating families were different in many ways, there was positivity about home education and broad agreement about their social experiences and beliefs, which perhaps helps to create a sense of community.

Future research could investigate the creation of more appropriate socialising opportunities for adolescents within the home educating community. Maria suggested that teenagers need a more relaxed kind of socialising than younger children. Socialising opportunities for adolescents exist within UK home education networks, but participants noted that activities and events are often targeted at younger children. This could explain why considerably fewer adolescents than children attend meetings organised by home education networks (FortuneWood 2006). Perhaps, teen socialising experiences are hard to create and/or are not successful enough to sustain. Socialising with peers is particularly important for healthy adolescent development, which requires more horizontal than vertical socialising typically seen in home education networks. Therefore, participatory action research with home educating families with adolescents could help to generate and trial some ideas. This has the potential to improve socialising for adolescents who are home educated by drawing on the knowledge and experience of the community.

This study provided an insight into the social lives of three UK home educated adolescents and the social opportunities that they participate in. The study has demonstrated the role of the home educating networks in bringing together families to create a sense of community, which can act as a support network for both parents and children. The community was noted as being diverse, particularly with the wide-age range that the children interacted with, which offered the children a variety of social interactions. Parents encouraged their children to socialise and organised positive social experiences, such as activities and groups to facilitate this. However, because the children were older, they had a large input into creating their social experiences.

Open Access This article is distributed under the terms of the Creative Commons Attribution 4.0 International License (http://creativecommons.org/licenses/by/4.0/), which permits unrestricted use, distribution, and reproduction in any medium, provided you give appropriate credit to the original author(s) and the source, provide a link to the Creative Commons license, and indicate if changes were made.

\section{References}

Arnett, J. (2000). Emerging adulthood: a theory of development from the late teens through the twenties. American Psychologist, 55(5), 469-480.

Berns, R. (2012). Child, family, school, community: socialization and support. Belmont: Wadsworth/Thomson Learning.

Braun, V., \& Clarke, V. (2006). Using thematic analysis in psychology. Qualitative Research in Psychology, 3(2), $77-101$. 
Brinkmann, S. (2014). Interview. In Encyclopedia of critical psychology (pp. 1008-1010). New York, NY: Springer.

Clarke, V., \& Braun, V. (2013). Teaching thematic analysis: overcoming challenges and developing strategies for effective learning. The Psychologist, 26(2), 120-123.

Collins, W., Maccoby, E., Steinberg, L., Hetherington, E., \& Bornstein, M. (2000). Contemporary research on parenting: the case for nature and nurture. American Psychologist, 55(2), 218-232.

Costanzo, P., \& Hoy, M. (2007). Intergenerational relations: themes, prospects, and possibilities. Journal of Social Issues, 63(4), 885-902.

Department for Education. (2013). Elective home education: guidelines for local authorities. Retrieved from https:/www.gov.uk/government/uploads/system/uploads/attachment_data/file/288135/guidelines_for_las_ on_elective home_educationsecondrevisev2_0.pdf.

Ditch the Label. (2015). The annual bullying survey 2015. Retrieved from http://www.ditchthelabel.org/wpcontent/uploads/2016/07/abs2015.pdf.

Eddis, S. (2015). A case of mistaken identity: Perspectives of home educators and state officials in England and Wales, and Florida, USA. In P. Rothermel (Ed.), International perspectives on home education: Do we still need schools? (pp. 99-109). Hampshire: Palgrave Macmillan.

Fortune-Wood, M. (2005). The face of home-based education 1: who, why and how. Nottingham: Educational Heretics.

Fortune-Wood, M. (2006). The face of home-based education 2: numbers, support, special needs. Nottingham: Educational Heretics.

Granovetter, M. (1973). The strength of weak ties. American Journal of Sociology, 78(6), 1360-1380.

Greig, A., Taylor, J., \& MacKay, T. (2012). Doing research with children: a practical guide (3rd ed.). London: SAGE.

Hogg, M., \& Abrams, D. (1990). Social motivation, self-esteem, and social identity. In D. Abrams \& M. Hogg (Eds.), Social identity theory: constructive and critical advances (pp. 44-70). London: Harvester Wheatsheaf.

Howarth, C. (2002). Identity in whose eyes? The role of representations in identity construction. Journal for the Theory of Social Behaviour, 32(2), 145-162.

Kraftl, P. (2013). Towards geographies of 'alternative' education: a case study of UK home schooling families. Transactions of the Institute of British Geographers, 38(3), 436-450.

Kunzman, R., \& Gaither, M. (2013). Homeschooling: a comprehensive survey of the research. Other education: The Journal of Educational Alternatives, 1, 4-59.

Lebeda, S. (2007). Homeschooling: depriving children of social development. Journal of Contemporary Legal Issues, 16, 99-104.

Medlin, R. (2000). Home schooling and the question of socialization. Peabody Journal of Education, 75(1-2), $107-123$.

Medlin, R. (2007). Homeschooled children's social skills. Home School Researcher, 17(1), 1-8.

Medlin, R. (2013). Homeschooling and the question of socialization revisited. Peabody Journal of Education, 88(3), 284-297.

Milkie, M., Bianchi, S., Mattingly, M., \& Robinson, J. (2002). Gendered division of childrearing: ideals, realities, and the relationship to parental well-being. Sex Roles, 47(1), 21-38.

Murphy, J. (2014). The social and educational outcomes of homeschooling. Sociological Spectrum, 34(3), $244-272$.

Nelsen, M. (1998). Beyond the stereotypes: home schooling as a legitimate educational alternative. High School Magazine, 6(2), 32-37.

Obradovic, S., \& Howarth, C. (2017). Social representations. In The Wiley-Blackwell Encyclopedia of Social Theory. Retrieved from https://doi.org/10.1002/9781118430873.est0361.

Osterman, K. (2000). Students' need for belonging in the school community. Review of Educational Research, $70(3), 323-367$

Parke, R., \& Clarke-Stewart, A. (2011). Social development. Hoboken: J. Wiley \& Sons.

Ray, B. (2013). Homeschooling associated with beneficial learner and societal outcomes but educators do not promote it. Peabody Journal of Education, 88(3), 324-341.

Reis, H., \& Wheeler, L. (1991). Studying social interaction with the Rochester Interaction Record. Advances in Experimental Social Psychology, 24, 269-318.

Renninger, K. (1998). Developmental psychology and instruction: issues from and for practice. In W. Damon, I. Sigel, \& K. Renninger (Eds.), Handbook of child psychology: Vol. 4. Child psychology in practice (5th ed., pp. 211-274). New York: Wiley.

Romanowski, M. (2006). Revisiting the common myths about homeschooling. The Clearing House: A Journal of Educational Strategies, Issues and Ideas, 79(3), 125-129.

Rose, A., \& Rudolph, K. (2006). A review of sex differences in peer relationship processes: potential trade-offs for the emotional and behavioural development of girls and boys. Psychological Bulletin, 132(1), 98-131. 
Rothermel, P. J. (2002) Home-education: rationales, practices and outcomes (doctoral dissertation). Retrieved from Durham e-Theses. (1005).

Smedley, T. (1992). Socialization of home schooled children: a communication approach (unpublished dissertation). Radford University, Virginia.

Socialisation. (2012). In Collins English dictionary. Retrieved from http://www.collinsdictionary. com/dictionary/english/socialization.

Staufenberg, J. (2017). Home education doubles, with schools left to 'pick up pieces' when it fails. Schools Week. Retrieved from https://schoolsweek.co.uk/home-education-doubles-with-schools-left-to-pick-uppieces-when-it-fails/.

Steinberg, L., Mounts, N., Lamborn, S., \& Dornbusch, S. (1991). Authoritative parenting and adolescent adjustment across varied ecological niches. Journal of Research on Adolescence, 1(1), 19-36.

Valdez, K. (2005) Social perception of home schooled students (unpublished doctoral dissertation). University of Kansas, Lawrence.

Vervoort, M., Scholte, R., \& Scheepers, P. (2011). Ethnic composition of school classes, majority-minority friendships, and adolescents' intergroup attitudes in the Netherlands. Journal of Adolescence, 34(2), 257267.

Wray-Lake, L., Crouter, A., \& McHale, S. (2010). Developmental patterns in decision-making autonomy across middle childhood and adolescence: European American parents' perspectives. Child Development, 81(2), 636-651.

Eloise de Carvalho. Department of Psychology, Keele University, Staffordshire, UK, ST5 5BG, UK, email: w0u78@students.keele.ac.uk

Current themes of research:

I am interested in developing interventions which encourage a growth mindset in young people as a way to help them to achieve their potential. I have a particular interest in working with marginalised children including home educated children and children with SEND.

Dr Yvonne Skipper. Department of Psychology, Keele University, Staffordshire, UK, ST5 5BG, UK y.skipper@keele.ac.uk

Current themes of research:

Social influences on learning. I am interested in how teachers and peers influence learners' subject choice and performance. I have conducted a number of experimental and intervention studies on this topic.

Most relevant publications in the field of Psychology of Education:

Leman, P. J., Skipper, Y., Watling, D., \& Rutland, A. (2016). Conceptual change in science is facilitated through peer collaboration for boys but not for girls. Child Development, 87, 176-183.

Skipper, Y. \& Douglas, K. (2016). The impact of a selective entry examination on children's feelings as they approach the transition to secondary school. British Educational Research Journal. Online Early View.

Skipper, Y., \& Douglas, K.M. (2015). The Influence of Feedback on Children's Perceptions of StudentTeacher Relationships British Journal of Educational Psychology, 85, 276-288.

Skipper, Y., \& Douglas, K.M. (2012). Is no praise good praise? Effects of positive feedback on children's responses to subsequent failures. British Journal of Educational Psychology, 82, 327-399. doi: 10.1111/j.2044-8279.2011.02028.x 